\title{
MRSBulletin
}

Gopal R. Rao

Editor, MRS Bulletin

rao@mrs.org

\section{Coincidence, the gift to gab, or the nature of scientists' global network?}

\section{To the Editor:}

Thanks for a great read and the invitation to comment on Bob Fleischer's column in POSTERMINARIES, published in the January 2011 issue of MRS Bulletin (p. 80). The article "Coincidence or hidden connections?" brought up unusual circumstances in which the author met someone who knew someone he knew. I would say we are drawing from the same well in terms of connections made in oddball places. I would argue that my frequency (and magnitude!) of such encounters is somewhat comparable to Bob's and certainly exceeds the norm. Thus I wonder how much the likelihood of these events is related to an accumulation of life experiences/associations considering I am somewhat younger than Bob when he wrote the column. Let me offer instead that, like Bob was, I am probably more likely to talk to people in the first place and dig a bit to look for connections. Personally, I will strike up a conversation with anyone and often prod a bit until we can find some common ground. I am hungry to interact with interesting people and thoroughly enjoy good conversation - which I tend to remember. Furthermore, being in the sciences put us both at an advantage (versus the non-scientist), I would suspect, given the network of conferences, publications, and the like. Thus, my conclusion is that certain people are more receptive or open to the possibility of such coincidences. Of course we would need a control experiment wherein we took a room full of people and had a few terabytes of data on each and look for overlaps! I bet there would be connections that would never be found if the folks did not gab.

\section{To the Editor:}

I came across Bob Fleischer's note in an online MRS web page about coincidences. Pretty amusing, though I suspect that many of us have had similar experiences. For example, I was at a historic ceremony in Piazza San Marco in Venice a while back, with thousands of people in the audience, and found that the fellow sitting next to me by chance was not only from Quebec City, but a former student of mine - in physics! Other than the fact that our ilk makes many connections through traveling to scientific meetings in many lands, university/academic people tend to gravitate toward people that have a similar background. When I lived in Europe, I noticed how Americans were always surprised at finding other Americans in a given area-not too surprising, as they tend to seek them out, consciously or not (for example, through European contacts who would steer them toward other Americans). Scientists also have offspring who are likely to attend university, and that is another mixer that generates contacts worldwide, no matter what their field of study. I do not know if you would find many "coincidences" with a fellow running a grocery store in Oswego or some even more remote place. It seems to me that when you cite your "coincidence" experiences, you are actually working with a fairly small subset of humanity that is "plugged in" to a whole bunch of very large networks. (By the way, I liked the graphic added to the note-it looks like a map to bathrooms within a beehive!)

Émile Knystautas Université Laval

Christopher L. Cahill George Washington University 
